\title{
Student Perceptions of Social Presence and Attitudes toward Social Media: Results of a Cross-Sectional Study
}

\author{
Joan S Leafman ${ }^{1}$, Kathleen M Mathieson ${ }^{1}$ \& Helen Ewing ${ }^{1}$ \\ ${ }^{1}$ Doctor of Health Sciences Program, Department of Interdisciplinary Health Sciences, Arizona School of Health \\ Sciences, A.T. Still University, USA
}

Correspondence: Joan S Leafman, Doctor of Health Sciences Program, Department of Interdisciplinary Health Sciences, Arizona School of Health Sciences, A.T. Still University, Mesa, Arizona 85206, USA. Tel: 1-480-219-6029. E-mail: jleafman@atsu.edu

Received: December 28, 2012

Accepted: January 24, $2012 \quad$ Online Published: January 28, 2013

doi:10.5430/ijhe.v2n1p67

URL: http://dx.doi.org/10.5430/ijhe.v2n1p67

\begin{abstract}
Establishing and maintaining social presence in an online environment that depends on a learning management system (LMS) can be challenging. While students believe social presence to be important, LMS platforms have yet to discover a way to deliver this expectation. The growth of social media tools presents opportunities outside an LMS to foster social presence in online learning communities. The purpose of this study was to assess perceived levels of social presence in an LMS and willingness to use social media tools outside an LMS among online doctoral students. Student perceptions of social presence and willingness to use a social media tool were examined via a descriptive, cross-sectional survey design. The sample size was 138, representing a 52\% response rate. Students reported high levels of social presence in the LMS, but noted important areas in which the LMS was deficient. While all students used at least one social media tool, the modes of communication with other students and instructors were primarily tradition (e-mail, LMS, phone). Despite their busy schedules, 57\% of respondents reported having greater than 30 minutes available daily for social connections with other students and instructors, and $43 \%$ indicated that they were willing to use a social media tool if one was offered outside of the LMS. Given the importance that students place on social presence, the limitations of the LMS and the willingness of students to experiment with a social media tool in their learning environment, the exploration of adding such a tool is warranted.
\end{abstract}

Keywords: Distance education, Online learning, Community of inquiry, Social presence, Social media, Social media tools

\section{Introduction}

Engaged learning can be challenging for educators, students, and administrators. This is especially true in an online environment. All of the elements that potentially hinder success in academic learning communities exist online but with the added obstacles of technology utilization, degree of reliance upon a learning management system (LMS) and the ill fit of the LMS with academic pedagogy (Casey \& Evans, 2011).

A crucial factor in promoting engaged learning is the development and maintenance of social capital. While social capital is a multi-faceted concept defined and described in a multitude of ways, it can be viewed as the mechanism that sustains communities, be they physical or virtual (Coleman, 1988; Fetter, Berlanga, \& Sloep, 2010; Fowler, 2012). At its heart, social capital is about shared trust, goodwill, support, and norms (Ellison, Steinfield, \& Lampe, 2007). This is as important, albeit more difficult to deliver, in a virtual learning community as it is in a traditional classroom setting. In an online environment, investment in social capital is often measured by "tie strength" (Grandovetter, 1973). Tie strength refers to social networking or interactivity (Chi, Chow, Chan, Seow \& Tam, 2009) and is dependent on duration and frequency of non-academic, student-to-student communication. Interestingly, while the quantity of social communication among students is considered paramount, the quality of those interactions is rarely measured and it is unclear whether an LMS can effectively facilitate this essential piece of the learning cycle. Also problematic is that non-academic interactions with facilitators, admittedly more difficult to assess, are often overlooked in studies of social capital and tie strength in online environments (Brazington, 2012; Cobb, 2009).

One method of supporting social capital in learning communities is by increasing social presence. Social presence is one of the three factors in Garrison, Anderson, and Archer's widely-used Community of Inquiry (CoI) framework (2000). The CoI framework proposes that academic success is interdependent on cognitive, teaching, and social 
presences. Of the three, social presence and its core elements of emotional expression, open communication, and group cohesion are, like tie strength, the most difficult to authentically incorporate in online learning environments.

Previous research contends that LMS such as Blackboard are structured to facilitate formal and monitored communication, and are therefore unable to provide adequate and meaningful social presence for participants (Quinn, 2010; Brazington, 2012; Richards, Rasli, Ahmad \& Chruchill, 2006). For many, the inadequacy of the LMS is acceptable because research has yet to provide a link between social presence and objective learning outcomes (Annand, 2011; Rourke \& Kanuka, 2009). However, even though a definitive relationship has not been established, student perceptions of the importance of social presence in online environments have consistently been positive (Akyol \& Garrison, 2008; Caspi \& Blau, 2008; Richardson \& Swan, 2003; Gunawardena \& Zittle, 1997).

Appreciating the value of social presence creates a dilemma for online education. While students believe that social capital, supported through social presence, contributes to their ongoing academic success, LMS platforms have yet to discover a way to fully deliver this expectation (Poellhuber \& Anderson, 2011). Fortunately, the rapid growth, availability, reasonable cost (often free) and easy access of participatory media, commonly referred to as social media, present many opportunities outside an LMS to foster social presence in online learning communities (Rheingold, 2008b). In its purest sense, social media is a well-defined and carefully constructed term. According to Rheingold (2008a) and Blankenship (2011), social media is comprised of three characteristics. First, it follows a pattern of "many-to-many" connections so that everyone who is connected has an equal and accessible voice. Second, it is participatory, meaning that everyone who is connected must be active at least some of the time. Finally, networking must occur so that collaboration is present and a common voice is heard. Social media tools are those Internet-provided digital information distribution networks that foster social media mobilization.

Despite the opportunities provided by social media venues via social media tools, institutional administrators and academic faculty are often reluctant, most often due to legal ramifications and discomfort with technology, to include such social presence boosting instruments in online learning environments (Magna, 2011; Blankenship, 2011; Brazington, 2012; Rheingold 2008b). Typically, attorneys and or legal counsel for academic institutions, virtual and face-to-face, insist on the need to consider legitimate limitations and responsibilities when offering social media outlets. Unanswered questions regarding use and misuse of social media tools currently plague the court system. Further, the potential for invasion of privacy and the stability of social media tools, and the comprehension of social norms and adherence to those norms continue to be a struggle. Thus, a primary issue for the incorporation of social media in an online learning environment is more about how to appropriately use the selected tool rather than which tool to select. Given the myriad of obstacles when including social presence via social media in online environments, policies and guidelines can be described as a moving target in that they cannot be static, and authentic value needs to be assessed in order to determine if the benefits justify the paradigm shift.

To this end, taking into account both the value of social presence and the potential limitations of most LMS platforms, examining alternate methods of fostering social presence is warranted. Therefore, the purpose of this study was to assess the perceived level of social presence and willingness to use a social media tool outside an LMS among online doctoral students. Although this study was exploratory, it was theorized that students would be reluctant to use a social media tool outside the LMS, primarily based on time constraints. This theory proved to be mistaken, thus opening the door to social presence inclusion efforts outside of an LMS platform.

\section{Methods}

\subsection{Participants}

This study was conducted in the Doctor of Health Sciences (DHSc) program at A.T. Still University (ATSU), Arizona School of Health Sciences. ATSU's DHSc program is a 70-credit, post-professional degree program for healthcare professionals. The program is blended, with $95 \%$ of coursework occurring online and $5 \%$ occurring during a one-week, on-site institute. The aim of the program is to foster students' skills in areas such as project management, decision-making, organizational management, evidence-based standards, and application of research to professional practice.

The mean age of students in the program is 43 years. Females represent $53 \%$ of students enrolled in the program. Student race/ethnicity is predominantly White (59\%), followed by African American (20\%), Asian or Pacific Islander (6\%), Hispanic (4\%), American Indian/Alaska Native (1\%), and other (10\%). A wide range of professions are represented in the program; $24 \%$ of students are physician assistants, $15 \%$ are health administrators, $13 \%$ are in academia, $9 \%$ are nurses, and $7 \%$ work in medical labs or research. The remaining $32 \%$ is comprised of diverse professions, including athletic trainers, respiratory therapists, social workers, and health and safety consultants. Program evaluation data show that students find the LMS easy to navigate and feel there are sufficient opportunities to collaborate with other students during their course of study. The program's graduation rate is $73 \%$.

\subsection{Study Design}

Student perceptions of social presence and willingness to use a social media tool were examined via a descriptive, cross-sectional survey design. The survey instrument included questions about demographic characteristics and current use of social media tools. Items from two previously validated instruments - the social presence scale 
developed by Gunawardena and Zittle (1997) and the social presence section of the Community of Inquiry measure developed by Arbaugh and colleagues (Arbaugh et al., 2008) - were included to measure students' perceptions of social presence in the LMS and to be as comprehensive as possible. In cases where items on the two instruments were redundant, only one was included in the survey. Students were also asked about the frequency of their social communication with other students and with instructors, and the media tools used for such communication (Facebook, LinkedIn, Twitter, Google+, and Skype). Finally, students were asked how likely they would be to use a social media tool if one was offered outside the LMS.

The link to the electronic survey instrument was delivered via e-mail to all current, full-time DHSc students ( $\mathrm{N}=263)$ via the program's Student Lounge in the LMS. The Student Lounge is a place to communicate with all students and a text based venue for discussions about professional and academic issues among the program's students, faculty, and administration. The survey instrument was available for four weeks, and three e-mail reminders were sent in weekly intervals to students, also via the Student Lounge. When the data collection period ended, data were downloaded into IBM SPSS Statistics version 19.0 for analysis. Frequencies, percentages, means, and standard deviations were calculated on all variables as appropriate. An overall measure of social presence was calculated by averaging the social presence items for each respondent. Cronbach alpha for the 14 social presence items was .84 , demonstrating internal consistency (Bland \& Altman, 1997).

\section{Results}

\subsection{Sample Characteristics}

One-hundred thirty-nine students completed the survey. One respondent, who noted that they were a graduate and thus no longer a current student, was excluded, resulting in a final sample size of 138 and representing a $52 \%$ response rate.

Characteristics of respondents are summarized in Table 1. Students tended to be between 31-50 years of age, female, and either White (64.5\%) or African American (20.3\%). These characteristics closely reflect the sex, age, and race/ethnicity profile of the program as a whole. The most common age groups were 31-40 years (30.4\%) and 41-50 years (32.6\%). Seventy percent of respondents either lived with a partner or with a partner and children. The median hours worked per week was 50, reflecting the post-professional nature of the program.

Table 1. Participant Characteristics

\begin{tabular}{ll}
\hline Characteristic & $\mathrm{n}(\%)$ \\
\hline Age, year & $11(8.0)$ \\
$21-30$ & $42(30.7)$ \\
$31-40$ & $45(32.8)$ \\
$41-50$ & $39(28.5)$ \\
$51+$ & $1(0.7)$ \\
Missing & \\
Sex & $81(58.7)$ \\
Female & $54(39.1)$ \\
Male & $3(2.2)$ \\
Missing & \\
Family status & $22(15.9)$ \\
Live alone & $38(27.5)$ \\
Live with partner & $58(42.0)$ \\
Live with partner and child(ren) & $9(6.5)$ \\
Live with child(ren) & $10(7.2)$ \\
Other & $1(0.7)$ \\
Missing & \\
Race/ethnicity & $89(64.5)$ \\
White & $28(20.3)$ \\
African American & $7(5.1)$ \\
Hispanic & $4(2.9)$ \\
Asian/Native Hawaiian/Pacific Islander & $3(2.2)$ \\
American Indian/Alaskan Native & $4(2.9)$ \\
Other & $3(2.2)$ \\
Missing & $50.0(30.0-85.0)$ \\
Median hours worked per week (minimum-maximum) &
\end{tabular}

Note. All values reported as n (\%) unless otherwise noted. 


\subsection{Outcomes}

All students reported using at least one of the social media tools included in the survey instrument; $37 \%$ used one tool of the tools listed, $42 \%$ used two, 17\% used three, and 4\% used all five. Facebook was the most common tool used, followed by LinkedIn, Skype, Google+, and Twitter. Use of mobile devices was common, with $66 \%$ of students reporting use of either a smartphone or tablet (Figure 1). Thirty-two percent of students reported socially communicating with other students often or very often, and $18 \%$ reported socially communicating with instructors often or very often (Figure 2). Despite the common use of Facebook and other social media, the modes of social communication with other students and instructors were predominantly via the LMS (Blackboard), e-mail, or phone; it was uncommon for students to socially communicate with other students or instructors via social media tools (Figure 3).

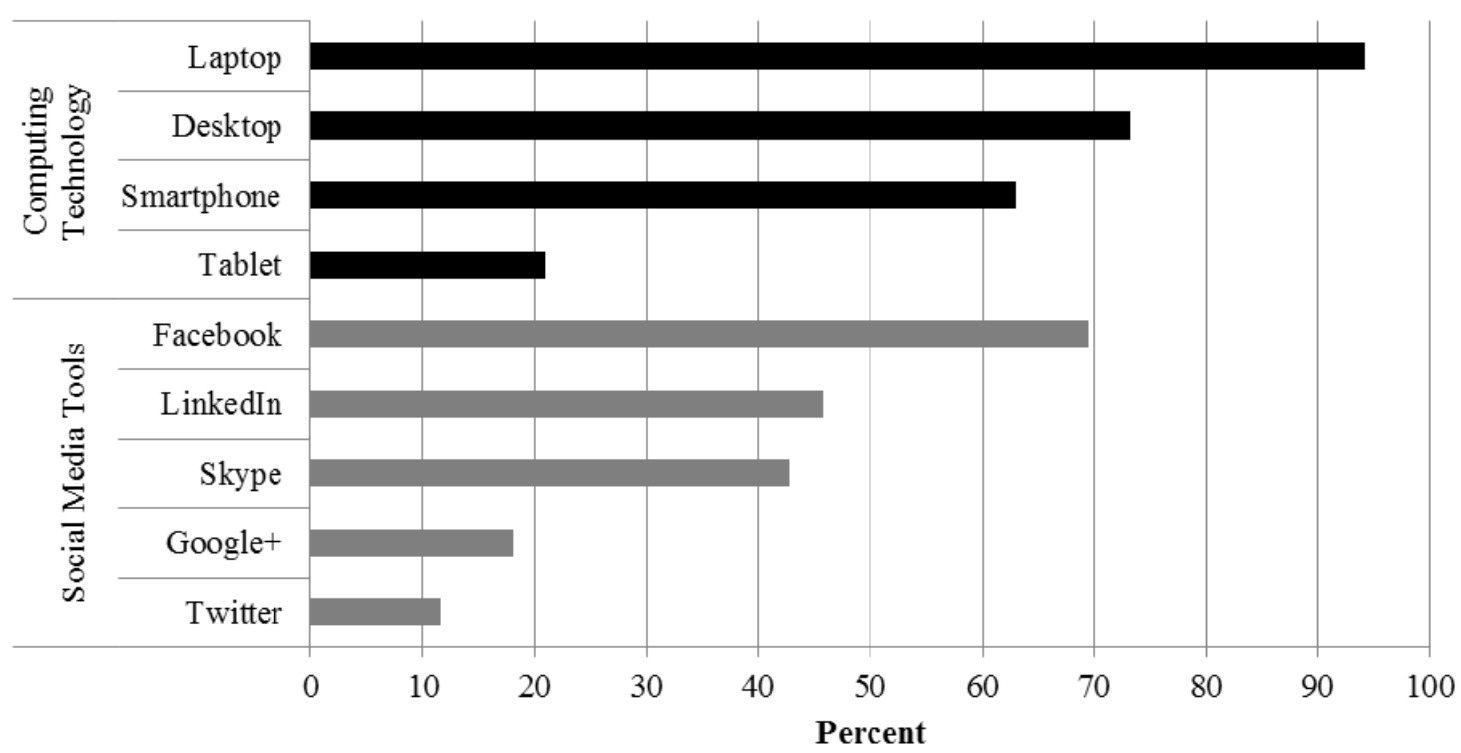

Figure 1. Current student use of computing technology and social media tools

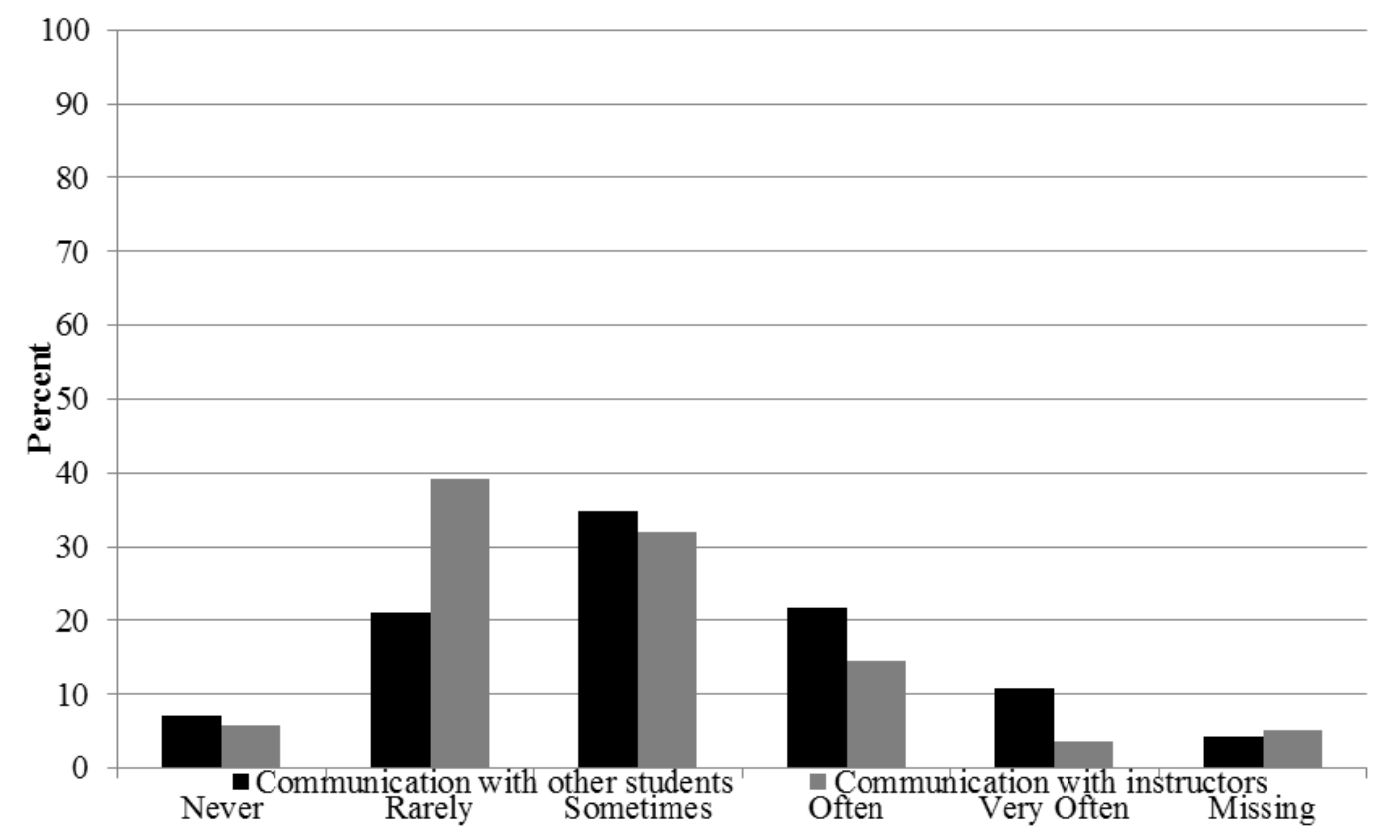

Figure 2. Social communication with other students and instructors 


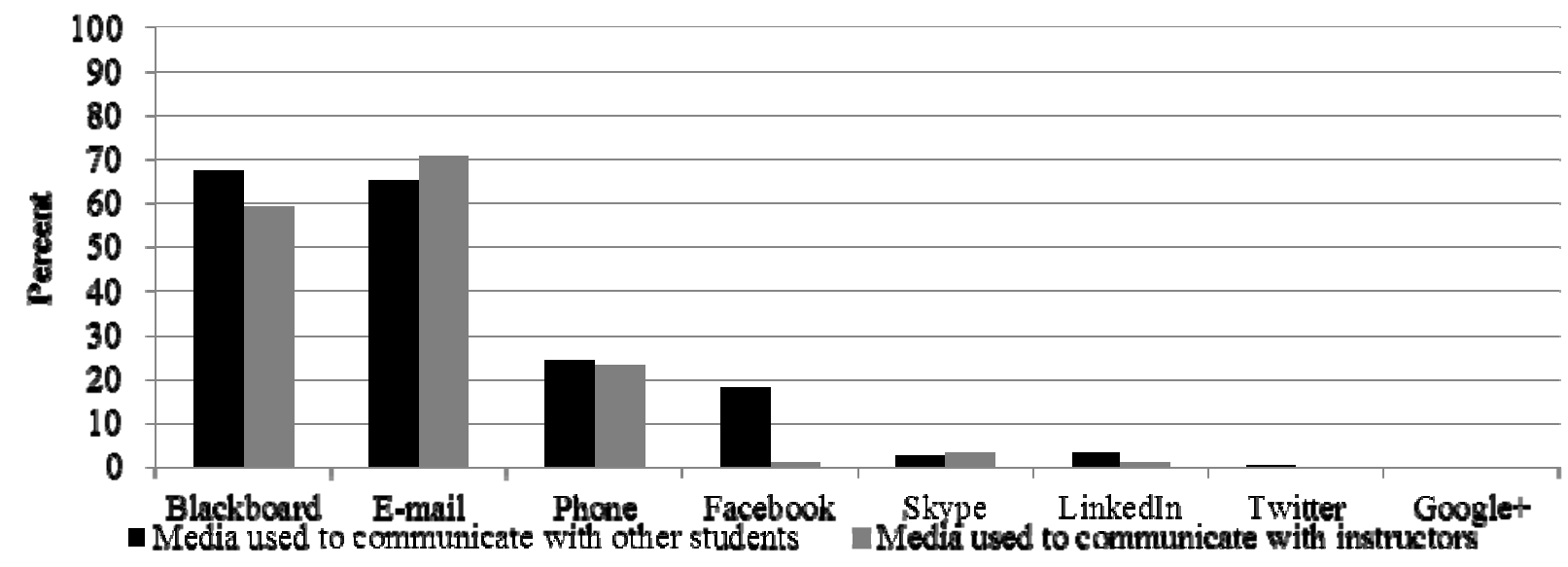

Figure 3. Media used to socially communicate with other students and instructors

The mean social presence score was $3.66( \pm .48)$, indicating that students generally perceived high social presence in the LMS. Responses to specific social presence questions showed that students were largely comfortable using Blackboard and using social media (Table 2). However, 65\% felt that discussions using Blackboard tended to be more impersonal than face-to-face discussions, and $49 \%$ felt that Blackboard discussions tended to be more impersonal than teleconference discussions. Similarly, $22 \%$ disagreed or strongly disagreed that communication through Blackboard is an excellent medium for social interaction; $25 \%$ were uncertain.

While only five students (4\%) reported having no time available daily for social communications with other students and instructors; $57 \%$ reported having greater than 30 minutes available per day for such connections (Figure 4). When asked about their willingness to use a social media tool if one was offered outside the LMS, $43 \%$ agreed or strongly agreed, 36\% were uncertain, and only 19\% disagreed or strongly disagreed (Figure 5).

Table 2. Student Perceptions of Social Presence

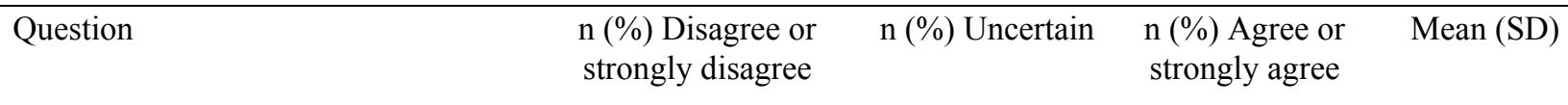

I feel comfortable participating in

$1(0.7)$

$7(5.1)$

$128(92.8)$

$4.32(0.61)$

Blackboard discussions.

I feel comfortable interacting with

$6(4.3)$

$128(92.8)$

$4.20(0.62)$

other course participants in

Blackboard.

I feel that my point of view is

16 (11.6)

$118(85.5)$

$4.09(0.67)$

acknowledged by other participants in

Blackboard.

I feel comfortable conversing through

$8(5.8)$

$13(9.4)$

$115(83.3)$

$4.01(0.78)$

Blackboard's text-based medium. 
The instructors create a feeling of an online community within Blackboard.

The introductions, in Blackboard, enable me to form a sense of online community.

In Blackboard, I feel comfortable disagreeing with other course participants while still maintaining a sense of trust.

I am very comfortable utilizing social media.

Online discussions in Blackboard help me to develop a sense of collaboration.

I am able to form distinct individual impressions of other participants using Blackboard.

The instructors moderate the discussions in Blackboard.

Discussions using the medium of Blackboard tend to be more impersonal than face-to-face discussions.

Communication through Blackboard is an excellent medium for social interaction.

Blackboard discussions tend to be more impersonal than teleconference discussions.

Messages on Blackboard are impersonal.
$10(7.2)$

$22(15.9)$

$105(76.1)$

$3.91(0.81)$

$16(11.6)$

$19(13.8)$

$103(74.6)$

$3.84(0.91)$

$12(8.7)$

$15(10.9)$

$111(80.4)$

$3.84(0.78)$

$18(13.0)$

$17(12.3)$

$103(74.6)$

$3.83(1.09)$

$13(9.4)$

$28(20.3)$

$97(70.3)$

$3.80(0.86)$

$14(10.1)$

$29(21.0)$

$95(68.8)$

$3.69(0.81)$

$25(18.1)$

$15(10.9)$

$96(69.9)$

$3.65(1.02)$

$32(23.2)$

$14(10.1)$

$90(65.2)$

$3.55(1.03)$

$30(21.7)$

$34(24.6)$

$74(53.6)$

$3.42(0.94)$

$3(2.2)$

$29(21.0)$

67 (48.6)

$3.22(1.00)$

$62(44.9)$

$22(15.9)$

$53(38.4)$

$2.93(1.08)$

Note. Valid percentages are presented. 


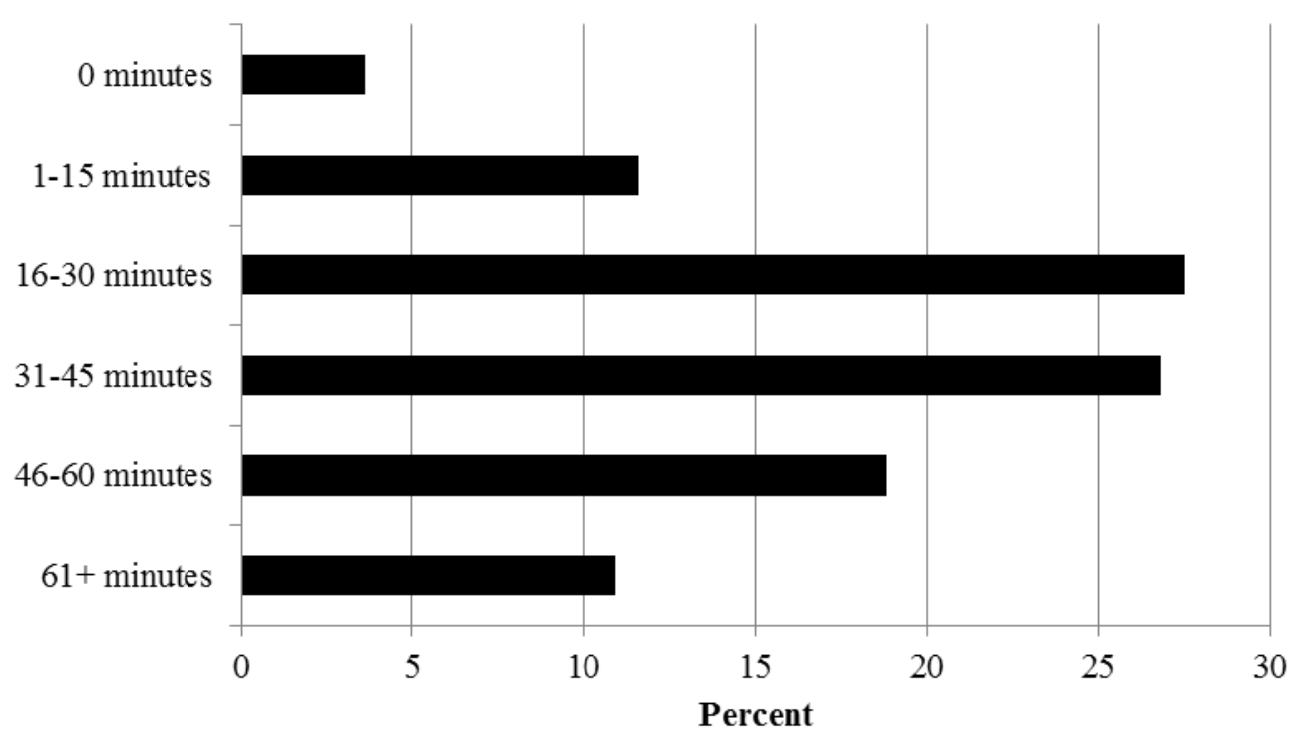

Figure 4. Time available for social connections with other students and instructors

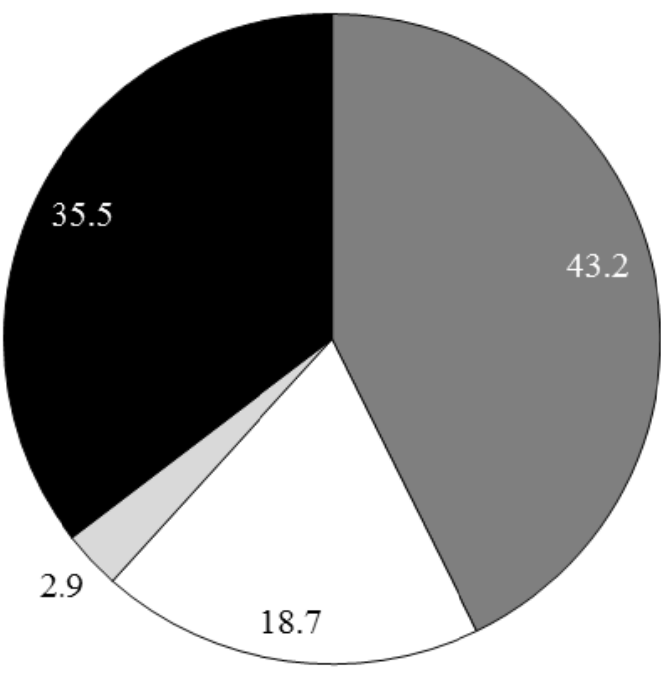

\section{Discussion}

$\square$ Agree or Strongly Agree $\quad \square$ Disagree or Strongly Disagree $\quad \square$ Other $\quad$ Unncertain

Figure 5. Willingness to use social media tool outside the learning management system

This study examined student perceptions of social presence in an LMS and their willingness to utilize social media tools outside of an LMS. As suggested in the literature, social presence is integral in developing social capital, which is the mechanism that sustains physical or virtual communities (Coleman, 1988; Fetter et al., 2010; Fowler, 2012). Social presence also has a positive effect on student satisfaction and possibly on student success (Akyol \& Garrison, 2008; Caspi \& Blau, 2008; Richardson \& Swan, 2003; Gunawardena \& Zittle, 1997). Commonly used LMS such as Blackboard, which are primarily driven by formally directed and monitored communication, are restricted in their ability to foster social presence. Thus, offering a virtual communication venue outside of the prescribed system to accommodate this critical and student desired aspect of online learning is essential. In addition, the ability of the Internet to seamlessly offer social or participatory media through digital social media tools coupled with online programs commitment to student centered learning - which clearly indicates a desire for social presence - should not be ignored. 
All students in this study reported use of some type of social media tool. However, within the academic realm, their standard modes of social communication with other students and instructors were primarily email, correspondence within the LMS, or teleconference. Most students did not use social media to socially communicate with each other or with instructors. This finding may be due to the absence of a formal effort from the faculty in the program to incorporate social media into the educational environment. Results of the study indicate that if a social media tool was introduced, use of such an instrument for social communications with peers and instructors would be welcomed by most students. Students were comfortable using and did perceive a high level of social presence within the LMS. This demonstrates that while the platform was not designed to foster or encourage non-academic communication, students found a way, at some level, to socially communicate. For example, research by Gunawardena and Zittle (1997) and Derks, Bos Arjan, \& von Grumbkow, (2007) showed that emoticons were commonly used in online platforms to express emotion in the absence of fact-to-face, synchronous social interactions. Of note, was that students also found the LMS to be more impersonal than face-to-face communication and were skeptical about its value as a medium for meaningful and or sustainable social interaction. This finding may be attributed to the monitored structure of the LMS, where students feel that all activity, including social communication, is observed and evaluated.

Social media tools offer "the intriguing possibility that by enhancing social interactions with and among students ... instructors can increase the overall quality of engagement in a given instructional setting and, thus, create a more effective learning environment" (Roblyer, McDaniel, Webb, Herman, \& Witty, 2010, p. 137). Use of social media tools can foster development of social presence via self-disclosure, which has been shown to increase student motivation and perceived learning and to promote a comfortable classroom climate (Mazer, Murphy, \& Simonds, 2007). Given the availability and affordability of social media tools as well as the portability and user-friendly obtainability of mobile technology social media applications, social communication among students outside of an LMS is easily attainable. Indeed, students in this study reported a high level of comfort with social media and also high use of mobile devices, which may foster the success of social media applications outside the LMS. This type and style of messaging is equally available for communication with and among instructors. In a global online environment where students and instructors may reside anywhere, free and seamless informal communication that functions either synchronously or asynchronously, verbally or in text with rich media options adds immeasurable benefits to an academic program, with few negative consequences.

Most of the doctoral students in this study were employed full time and had immediate and/or extended family commitments; the median hours worked per week was 50 and $70 \%$ of students lived either with a partner or with a partner and children. Despite these work, school, and family commitments, it is striking and a revelation that over half of students reported having more than 30 minutes per day for social connections with other students and instructors. A social media tool offered outside the LMS is a user-friendly, easily accessible, and familiar method to incorporate social presence and non-academic connections. Indeed, $43 \%$ of students were open to such a tool used in this context. This important and novel result diverges from the findings of Roblyer and colleagues, which revealed that university students were ambivalent about using Facebook and similar technologies in education even though they used Facebook (2010). However, our findings revealed that roughly one-third of students were uncertain about using a social media tool outside the LMS, which may suggest that students need more information about these tools or experience with them in an online learning environment to fully determine their value.

These results, while exciting, must be coupled with important considerations prior to adoption of social media tools in an academic setting. One important consideration is the attitudes and technological savvy of faculty members. For example, Roblyer et al. (2010) found that faculty used Facebook less and were more skeptical about its use in education compared to students. This may create a new dilemma if a social media tool is added outside an LMS and students are willing to use such a tool, but faculty are reluctant. Its incorporation and sustainability will fail if all members of the educational community or CoI are not committed to its success. Furthermore, willingness to use such tools may depend on student characteristics such as age and gender. For example, Poellhuber and Anderson found that older students showed more interest in using social software for learning (2011). Thus, it is important to carefully consider the purpose, context, and student population prior to incorporating a social media tool in an educational setting.

Privacy and ethical implications must also be considered (Bugeja, 2006). A survey of over 800 faculty found mixed opinions on the use of social media in both in-person and virtual classrooms (Magna, 2011). Many cited the danger of crossing the personal and professional boundary and of potential violations of privacy laws such as the Family Educational Rights and Privacy Act (FERPA) and the Health Insurance Portability and Accountability Act (HIPAA) (e.g., when the social media tool is used during clinical coursework among students in healthcare programs). Other faculty respondents were eager to leverage students' widespread use of social media, noting that it can be an effective medium for fostering engagement. As one respondent noted, "It has the potential to engage students with their professors and ... for professors to reach out to them and appear more approachable" (Magna, 2011, p. 28). This is exactly what is needed as a supplement to LMS platforms when attempting to increase social presence. Indeed, Mack, Behler, Roberts, and Rimland (2007) discuss Facebook as an outreach tool for academic librarians, 
stressing the importance of personal disclosures that let students know you are approachable while emphasizing that professionalism must be maintained. To strike this balance can no doubt be difficult. Despite the obstacles, the benefit of increased social presence and the positive outcomes associated with it are certainly worth the investment.

To this end, the results of this study may support prior research conducted on the importance of social presence. For example, Cobb (2009) found students were comfortable with a variety of social media tools and thought social presence was important and closely tied to satisfaction. Studies by Akyol and Garrison (2008), Caspi and Blau (2008), and Richardson and Swan (2003) also supported these results. Frequency of social communication was addressed by Chi, et. al (2009); Ellison, Steinfield, and Lampe (2007); and Poellhuber and Anderson (2011). Their results supported this study's findings that the majority of students are familiar with and regularly use social media tools. Further support of this study's findings is evident in the work of Kumar, Dawson, Black, Cavanaugh, and Sessums (2011), which indicated that while students perceived social presence to be important they were dissatisfied with the LMS's ability to promote it. Finally, the results of this study indicated that the majority of students are either open to or uncertain about using a social media tool outside of the LMS. These results were similar to those of Casey and Evans (2011) and Enriquez (2010). Unique to this study, and most encouraging is that the majority of students reported having 30 minutes or greater daily to commit to social media via a social media tool. In Facebook (or the like) time, that is huge. This result offers the potential of sustainable, inexpensive, and successful social presence for online programs via the use of social media tools outside the LMS.

Conversely, the findings of Wanstreet and Stein (2011) suggest that, while social presence is identified as important by students both in face to face and online classrooms and may support cognitive presence in face to face classrooms, in online learning communities no such tie is evident. In both face to face and online learning environments, social presence and teaching presence are not significantly correlated (Shea et al., 2010) which is thought to be a result of student inexperience with social media and the limitations of the LMS (Demski, 2012). In this study students displayed interest in social presence to the point that they were willing to try a social media tool outside of the LMS in an effort to increase social presence. While significant ties to cognitive and teaching presence, important anchors of the CoI model, may not yet have been established, social presence, as a stand-alone is of great interest to students. This study reveals that with little difficulty, social media tools may be successfully offered outside of the LMS to sustain social presence. This type of functionality will well serve online programs with missions to foster student centered learning.

Several limitations of this study should be noted. First, the sample was comprised of one program, with questions pertaining to one specific LMS. The findings therefore may not be representative of students in other programs or using other LMS. Second, the constantly evolving nature of the LMS makes it difficult to establish definitive and concrete evidence of learning outcome characteristics like social presence. Features, particularly focused on issues surrounding social presence, are added and omitted from LMS platforms weekly. Finally, questions from two previously validated instruments were combined and modified to avoid repetition. This may have compromised measurement validity. However, the Cronbach alpha for the social presence scale (.84) indicated internal consistency and was similar to that reported in past research (Gunawardena \& Zittle, 1997).

\section{Conclusion}

Overall, the results of this study indicate that, while students were comfortable using the LMS, they found it lacking for social communication and were willing to try using a social media tool offered outside the LMS. This is an important finding because the creation of social capital through social presence is an essential student centered piece of a learning community, be it face-to-face or virtual. Student willingness to participate in some type of social media tool is encouraging. The true task ahead is to identify such a tool, making sure that it is easily accessible, used appropriately and that its value is sustainable. Further research in this area is warranted.

Moreover, despite their busy schedules, students reported having time available for daily social communications with other students and instructors. This finding was both unexpected and encouraging. Given the value placed on social presence by students and the obstacles that online programs face when instructing through an LMS, time to invest in social connections is a valuable discovery. Capitalizing on that available time, without overwhelming students, and remaining true to the basic communication concepts of social capital, social presence and participatory media via widely available and easily accessible tools will be a significant yet worthwhile challenge. Certainly, this warrants further investigation.

An additional opportunity for further research rests with faculty. Little is known of their perceptions of the value of social presence, use of social media, time available for social connections with students and colleagues, and willingness to use a social media tool outside the LMS to foster such connections. As important as understanding student attitudes, perceptions and willingness to embrace social media outside an LMS is knowledge of online faculty, administrators and facilitators. Social capital, social presence and the entire CoI model require full investment from all community members. Successful and sustainable incorporation of a social media tool may rest heavily on a special kind of non-directed, non-authoritative faculty participation. Willingness to engage in such 
communication needs to be assessed and analyzed prior to offering a tool to students in order to assure that its function affords added benefits.

Finally, it is not just if and "what" social media tools are used in online programs using LMS platforms, but "how" that is important. When attempting to increase communication among students and faculty and build social capital and social presence within an online course or program, it is important to do it well. Potential obstacles like cyber bullying or dominating a conversational exchange need to be recognized and diminished. Who leads this path is unclear. If all members are equal in a virtual social setting, then the assumption that faculty are responsible may be erroneous. These gaps in perceptions can have serious implications for practice and merit additional investigation.

\section{References}

Akyol, Z. \& Garrison, D. R. (2008). The development of a community of inquiry over time in an online course: Understanding the progression and integration of social, cognitive, and teaching presence. Journal of Asynchronous Learning Networks, 12(3), 3-22.

Annand,J. (2011). Social Presence within the Community of Inquiry Framework Annand. Review Literature and Arts of the Americas, 12(5), 1-10.

Arbaugh, J. B., Cleveland-Innes, M., Diaz, S. R., Garrison, D. R., Ice, P., Richardson, J. C., \& Swan, K. P. (2008). Developing a community of inquiry instrument: Testing a measure of the community of inquiry framework using a multi-institutional sample. Internet and Higher Education, 11(3), 133-136. http://dx.doi.org/10.1016/j.iheduc.2008.06.003

Bland, J.M. \& Altman, D.G. (1997). Statistics notes: Cronbach's alpha. British Medical Journal, 314, 572. http://dx.doi.org/10.1136/bmj.314.7080.572

Blankenship, M. (2011). How social media can and should impact higher education. Outlook, 21(March), 11-12. [Online] http://findarticles.com/p/articles/mi_hb3184/is_20101129/ai_n56465985/pg_2/?tag=mantle_skin;content

Available:

Brazington, A. (2012). Letting go. Campus Technology, April, 17-20.

Bugeja, M. J. (2006). Facing the Facebook. New York, 52(21), C1. http://dx.doi.org/10.1016/0277-9536(93)90295-F

Casey, G., \& Evans, T. (2011). Designing for learning : Online social networks as a classroom environment. The International Review of Research in Open and Distance Learning, 12(7), 1-26. [Online] Available: http://www.irrodl.org/index.php/irrodl/article/view/1011/2021

Caspi, A., \& Blau, I. (2008). Social presence in online discussion groups: Testing three conceptions and their relations to perceived learning. Social Psychology of Education, 11(3), 323-346. http://dx.doi.org/10.1007/s11218-008-9054-2

Chi, L., Chan, W. K., Seow, G., \& Tam, K. (2009). Transplanting social capital to the online world: Insights from two experimental studies. Journal of Organizational Computing and Electronic Commerce, 19(3), 214-236. http://dx.doi.org/10.1080/10919390903041931

Cobb, S. C. (2009). Social presence and online learning : A current view from a research perspective. Journal of Interactive Online Learning, 8(3), 241-254.

Coleman, J. S. (1988). Social capital in the creation of human capital. American Journal of Sociology, 94(1988), S95-S120. http://dx.doi.org/10.1086/228943

Demski, J. (2012). Rebuilding the LMS for the $21^{\text {st }}$ century. Campus Technology, April 2012. 35-37.

Derks, D., Bos Arjan, E. R., \& von Grumbkow, J. (2007). Emoticons in computer-mediated communication: Social motives and social context. CyberPsychology \& Behavior, 11(1): 99-101. http://dx.doi.org/10.1089/cpb.2007.9926

Ellison, N. B., Steinfield, C., \& Lampe, C. (2007). The benefits of Facebook "friends": Social capital and college students' use of online social network sites. Journal of Computer-Mediated Communication, 12(4), 1143-1168. http://dx.doi.org/10.1111/j.1083-6101.2007.00367.x

Enriquez, J. G. (2010). Fluid centrality: A social network analysis of social: Technical relations in computer mediated communication. International Journal of Research and Method in Education, 33(1), 55-67. http://dx.doi.org/10.1080/17437271003597915 
Fetter, S., Berlanga, A. J., \& Sloep, P. (2010). Fostering social capital in a learning network: Laying the groundwork for a peer-support service. Learning, 5(3), 1-19. [Online] Available: http://inderscience.metapress.com/index/Q6W61L847G4136G0.pdf

Fowler, Z. (2012). Learning communities and imagined social capital: Learning to belong. British Educational Research Journal, 38(1), 177-178. http://dx.doi.org/10.1080/01411926.2011.605270

Garrison, D. R., Anderson, T., \& Archer, W. (2000). Critical inquiry in a text-based environment: Computer conferencing in higher education. The Internet and Higher Education, 2, 87-105. http://dx.doi.org/10.1016/S1096-7516(00)00016-6

Granovetter, M. S. (1973). The strength of weak ties. American Journal of Sociology, v 78(6), 1360-1380. http://dx.doi.org/10.1086/225469

Gunawardena, C. N., \& Zittle, F. J. (1997). Social presence as a predictor of satisfaction within a computer-mediated conferencing environment. American Journal of Distance Education, 11(3), 8-26. http://dx.doi.org/10.1080/08923649709526970

Kumar, S., Dawson, K., Black, E. W., Cavanaugh, C., \& Sessums, C. D. (2011). Applying the community of inquiry framework to an online professional practice doctoral program. The International Review of Research in Open and Distance Learning, 12(6), 126-142. [Online] Available: http://www.irrodl.org/index.php/irrodl/article/view/978

Mack, D., Behler, A., Roberts, B., \& Rimland, E. (2007). Reaching students with Facebook: Data and best practices. Electronic Journal of Academic and Special Librarianship, 8(2), 4. [Online] Available: http://southernlibrarianship.icaap.org/content/v08n02/mack_d01.html

Magna, A. (2011). Social media usage trends among higher education faculty, (September). Faculty Focus Special Report. $2011 . \quad$ [Online] Available: http://www.facultyfocus.com/wp-content/uploads/images/2011-social-mediareport.pdf

Mazer, J. P., Murphy, R. E., \& Simonds, C. J. (2007). I'll see you on "Facebook": The effects of computer-mediated teacher self-disclosure on student motivation, affective learning, and classroom climate. Communication Education, 56(1), 1-17. http://dx.doi.org/10.1080/03634520601009710

Poellhuber, B., \& Anderson, T. (2011). Distance students' readiness for social media and collaboration. The International Review of Research in Open and Distance Learning, 12(6), 103-125.

Quinn, J. (2010). Learning communities and imagined social capital. London, England: Continuum.

Rheingold, H. (2008a). "Using participatory media and public voice to encourage civic engagement. The MIT Press. 97-118. http://dx.doi.org/10.1162/dmal.9780262524827.097

Rheingold, H. (2008b). Using social media to teach social media. New England Journal of Higher Education, 23(1), 25-26. [Online] Available:

http://www.eric.ed.gov/ERICWebPortal/contentdelivery/servlet/ERICServlet?accno=EJ850702

Richards, C., Rasli, A., Ahmad, U. K., \& Churchill, D. (2006). The online social networking of higher education academic communities. Proceedings of Global Learn Asia Pacific, 1364-1371.

Richardson, J. C., \& Swan, K. (2003). Examining social presence in online courses in relation to students' perceived learning and satisfaction. Journal of Asynchronous Learning Networks, 7(1), 68-88.

Roblyer, M. D., McDaniel, M., Webb, M., Herman, J., \& Witty, J. V. (2010). Findings on Facebook in higher education: A comparison of college faculty and student uses and perceptions of social networking sites. The Internet and Higher Education, 13(3), 134-140. http://dx.doi.org/10.1016/j.iheduc.2010.03.002

Rourke, L., \& Kanuka, H. (2009). Learning in communities of inquiry: A review of the literature. Journal of Distance Education, 23(1), 19-48.

Shea, P., Hayes, S., Vickers, J., Gozza-Cohen, M., Uzuner, S., Mehta, R., Valchova, A., \& Rangan, P. (2010). A reexamination of the community of inquiry framework: Social network and content analysis. The Internet and Higher Education, 13(1-2), 10-21. http://dx.doi.org/10.1016/j.iheduc.2009.11.002

Wanstreet, C. E., \& Stein, D. S. (2011). Presence over time in synchronous Communities of Inquiry. American Journal of Distance Education, 25(3), 162-177. http://dx.doi.org/10.1080/08923647.2011.590062 